\title{
Sharing Economic Accounting under the "Internet +" Mode - Taking Shared Bicycles as an Example
}

\author{
Li Li \\ Yunnan Technology and Business University, Yunnan, China, 651700
}

Keywords: Shared economy; shared bicycle; operating model; sustainable

Abstract: The sharing economy is a new business model based on the integration of offline idle resources. Since 2010, the sharing economy has developed rapidly on a global scale. The capital of various parties has been injected one after another. Many shared economic derivatives and shared brands have been born. However, under the rapid development of the sharing economy, problems such as incompatibility with the institutional environment have emerged. This paper takes shared bicycle as an example to analyze the current situation of domestic shared bicycle operation and learn from the successful experience of foreign shared bicycle operation and then put forward the specific countermeasures for the sustainable development of domestic shared bicycle.

\section{Shared bicycle operation status and problems}

China's shared bicycle market is still in its infancy. In 2015, the concept of shared bicycles began to rise. In 2016, the shared bicycle industry rose rapidly. As of March 2017, the financing of the shared bicycle industry has reached 7 billion yuan. There are more than 30 bicycle brands and the competition in the industry has become increasingly fierce. Shared bicycles have experienced three stages of development: the first stage is a pile of bicycles managed by the government and the second stage is a pile of bicycles contracted by the enterprise; the third stage is a pile-free Internet sharing dominated by enterprises. bicycle. Sharing bicycles has become a hot spot, leading the new trend of green travel and has become one of the important means of urban governance. It has outlined a wonderful stroke for urban smart transportation, but behind its rapid development, there are many shortcomings. Mainly as follows:

\subsection{Management conflict highlights}

At present, management conflicts are becoming more and more obvious in the immature shared economic system. First, conflict with the public environment. First- and second-tier cities share a large amount of investment in bicycles. The contradiction between the demand for parking space and the scarcity of urban public land resources is prominent and the phenomenon of "occupation of the road" has occurred, which has disrupted the public environment. Secondly, conflicts with traditional urban management. Traditional urban management regulations have never touched the sharing economy and the influx of shared bicycles has also presented new challenges to urban management; finally, conflicts with property management. Many users park their bicycles in the 
community downstairs and even occupy the parking lot, which increases the trouble and workload of property management ${ }^{[1]}$.

\subsection{Low profitability and difficulty in survival}

The profit of shared bicycles mainly depends on deposit deposit income, rental income, advertising revenue and traffic revenue. Large-scale operation is the premise of sharing bicycle profit. The shared bicycle market is like a cake. At present, many shared bicycle brands have risen. The same cake has been divided by many brands and the scale effect is not obvious. From the perspective of operating costs, the cost of sharing bicycles in the market ranges from 300 to 2,000 yuan and the rate of damage and maintenance is high. When the capital market is sluggish, the deposit flow cannot fill the cost gap at all and the operating costs are extremely high. Many companies have been suffering from debts and are facing bankruptcy ${ }^{[2]}$.

\subsection{High technical risk}

Most of the shared bicycle companies adopt commissioned production, so the technical risk is high. According to the Shanghai Bicycle Association survey, in addition to Mobai has its own production base, other companies mainly entrust other bicycle production enterprises to produce. If the shared bicycle company does not have a sound production standard, it is prone to the lack of control of the production enterprise and the quality is difficult to guarantee. The media reported that the quality of bicycles caused problems, resulting in personal injury to users, sharing bicycles with safety hazards, reflecting the low standard of bicycle technology.

\subsection{The credit crisis is serious}

Users frequently complain that "returning the deposit is difficult", complaining about the refund to the account, the money for recharging the fare is difficult to return, the telephone hotline does not support the manual service and the handling method is troublesome. The problem of sharing the deposit of a bicycle causes the user to have doubts or resistance to the company, the brand and even the shared bicycle itself, which constitutes a credit crisis for the enterprise. According to the report of China Business News on November 24, 2017, Xiaoming's bicycle was owed arrears of about 150 employees' wages and the deposit was not known. In addition, users also have a credit crisis. All kinds of damaged bicycles are flooding the streets, indicating that there is a big gap in the credit of bicycle users $^{[3]}$.

\section{Foreign experience in sharing bicycle operation}

\subsection{Development of shared bicycles abroad}

Throughout the world, sharing bicycles is not a new thing. It originated in the Netherlands and has undergone four generations of model evolution. The first generation, originated in Amsterdam, the Netherlands in 1965, the government invested in ordinary bicycles, free for the public to use, is a purely public welfare project, does not have a fixed site, with the use of; the second generation, in 1995 in Copenhagen, Denmark, the vehicle customization, There is a fixed pile site, the coin is unlocked, free to use, the vehicle is returned to any site and returned to the coin; the third generation, which appeared in Rennes, France in 1998, the shared bicycle officially turned into a public welfare commercial project, using a smart card to pick up the car, The first 30 minutes are free and a small fee is charged for the extra time; the fourth generation was first put into operation in Budapest, 
Hungary in 2005. The technology has advanced by leaps and bounds and built-in GPS, smart lock and other electronic devices have introduced APP search vehicles. The most successful shared bicycle promotion is France. In 2007, Velib shared the project by the Mayor of Paris and Bertrand Delano of the French Socialist Party. It shared the world's highest record with 130 million usage per year and attracted 224,000 members. Yes - one of the three Parisians is riding a Velib bike ${ }^{[4]}$.

\subsection{Successful experience in sharing bicycle operations abroad}

(1) A sound credit system. In the sharing economy, credit is an extremely important factor that needs to be established for a long time. How to provide the required services for unfamiliar users and reach a transaction in the virtual space is the important significance of the credit system. A sound credit system is conducive to the development of shared bicycles in a healthy and orderly manner. The credit system of Western countries has developed relatively maturely. For example, the US credit system is market-oriented, supplemented by the supervision of the government and the Federal Reserve. It is based on individuals, mainly including individuals, bank credit consumption and online and offline shopping. Information about each aspect. The problem of sharing bicycles has been declining year by year. As shown in Figure 1, various risk indices are steadily decreasing.

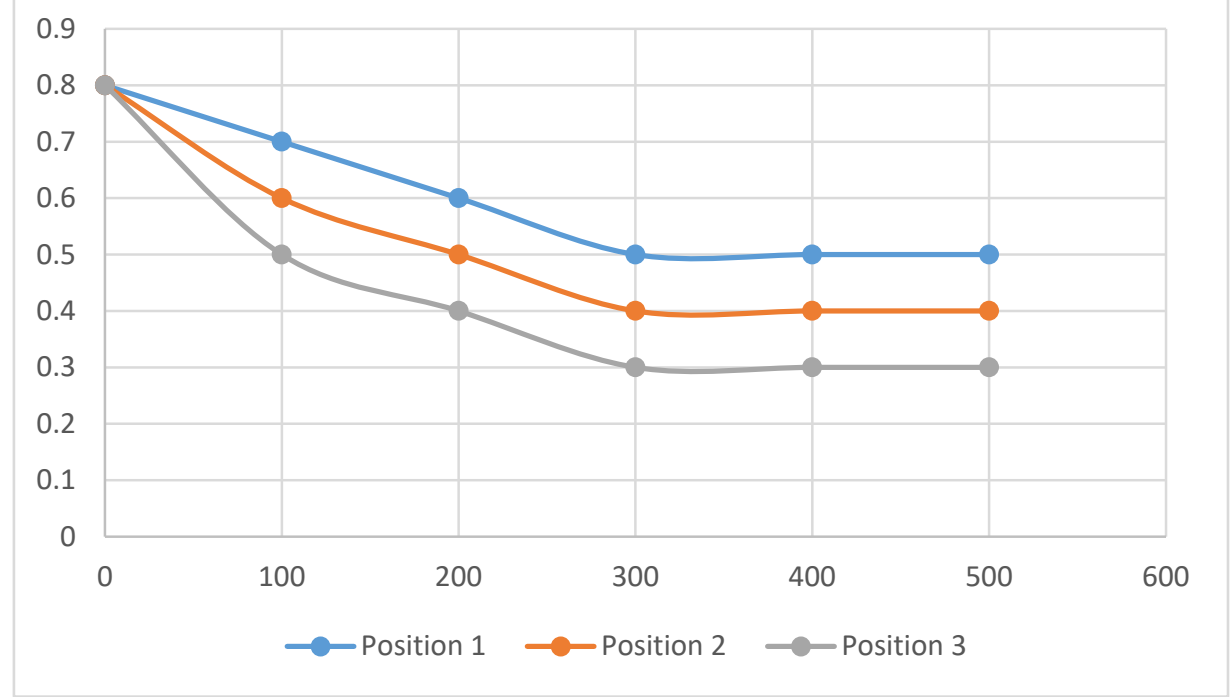

Figure 1 Various risk indices are steadily decreasing

(2) A positive political environment. Foreign government agencies attach great importance to system construction, keep pace with the times, strengthen the cultivation of laws and regulations and constantly improve the rules and regulations. At the same time, according to the characteristics of different industries, the government fully considers the feasibility of its access and formulates a "negative list". Legalize the name of the shared economic platform. For example, France passed a bill that stipulates that net-cars and shared-sector workers with a certain income are included in the freelancer's category and operate legally under the premise of corresponding taxes, marking the officially recognized sharing of France, the most developed European sharing economy. The legitimacy of the economy.

\section{Specific measures for domestic shared bicycle operation}

\subsection{Implement diversified operations and take the road of sustainable development}

Enterprises to revitalize the "deposit pool" and implement a diversified business strategy is the 
first choice for sustainable development. Shared bicycle companies can make full use of their own advantages, tap the potential of resources, expand business from the front and back of the industry chain and create profit points. For example, taking leisure and entertainment, green travel and health and wellness needs as the entry point, planning urban short-distance leisure cycling activities; and launching advertising service business. On July 3, 2017, the shared bicycle OFO officially launched Universal Studios' animated character "Xiaohuangren" customized bicycle; joint marketing with tourist attractions, introducing different types of bicycles, such as children's professional bicycles, double-seater bicycles, Mountain bikes, etc., provide a regular riding tour experience to meet the different riding needs of users ${ }^{[5]}$. The effect of diversified development and management is shown in Figure 2.

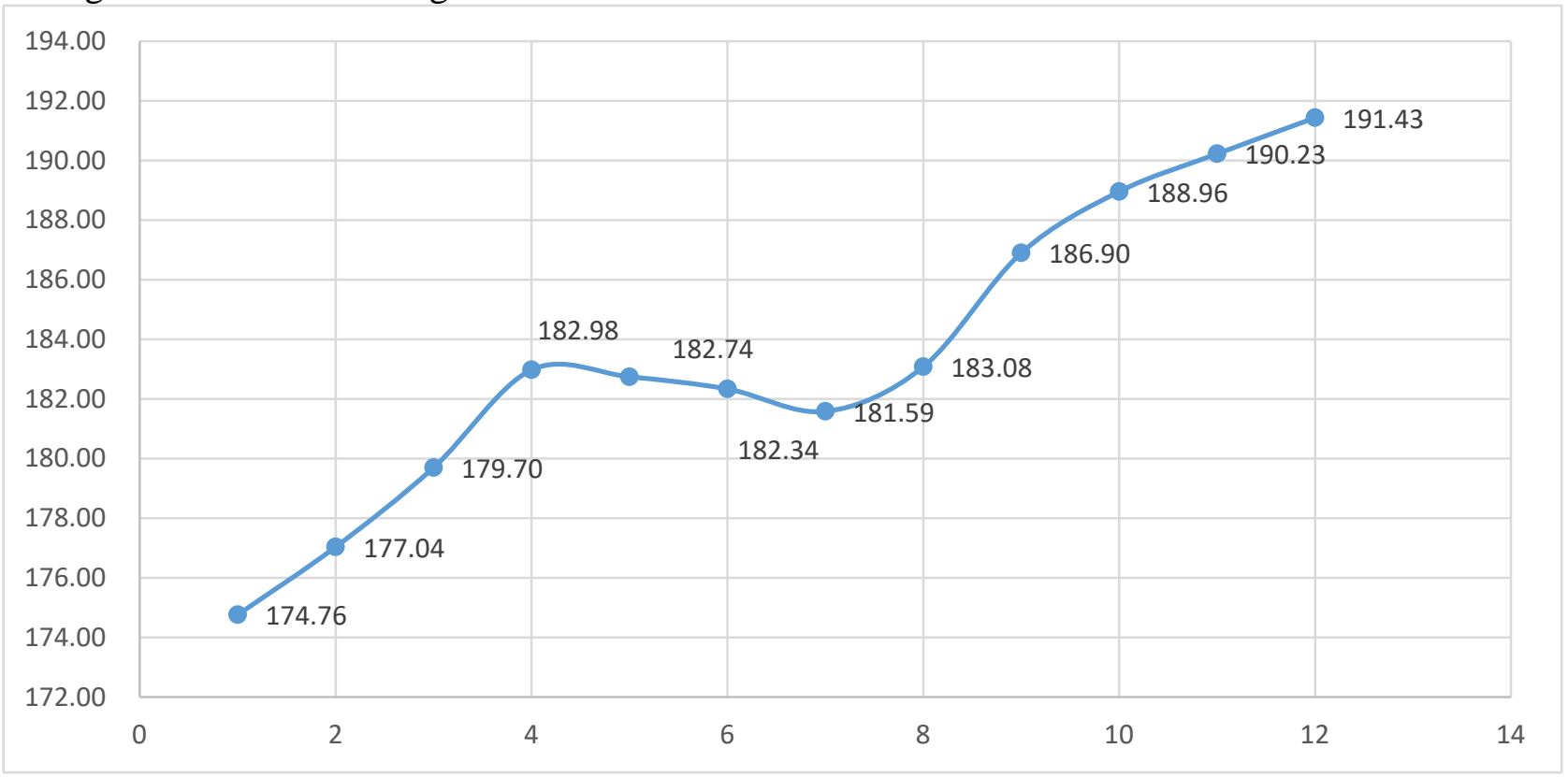

Figure 2 Effect of diversified development and management

\subsection{Rooted in sharing ideas and cultivating public civilization}

The development of the sharing economy requires the sharing concept of the public. The concept of sharing requires the public to protect the shared property and make it profitable. The establishment of a shared concept requires the efforts of all parties. The premise of shared concept recognition is to make users aware of the benefits of sharing. Enterprises should first provide quality services to enhance user satisfaction, such as timely replacement of bicycles, accurate GPS positioning and optimization of follow-up services, so that users can truly feel the importance of sharing bicycles in life; the government should speed up the improvement of urban bicycle lane planning Clearly divide the bicycle parking area to facilitate the citizens to travel green. Public civilization is also very important. The essence of shared bicycles is sharing and each user is obliged to protect bicycles during the period of use. Enterprises and governments should actively promote shared bicycle safety education. For example, Limebike in the United States has set up a registration course for cycling education on mobile apps to remind people to ride safely.

\subsection{Carry out government-enterprise cooperation and provide organizational guarantee}

The cooperation between government and enterprises is the key to solving the problem of domestic shared bicycle operation. First, the government and enterprises from the perspective of 
urban planning, such as the most difficult problem of oversupply at present, the government can help companies to recycle "zombie bicycles", repair and replacement by enterprises; in addition, planning of parking areas, not only It can solve the problem of parking chaos and it can also realize the optimal allocation of resources. For example, Japan built an underground bicycle parking tower in 2003. The planning of bicycle lanes and the construction of windproof and rainproof sheds are also considered. Secondly, the government can proceed from the perspective of system formulation, which can cover aspects such as cycling education, traffic rules, cycling equipment requirements and age restrictions. Finally, the government and enterprises should jointly improve the social credit system, establish a comprehensive credit model by connecting with the credit systems of various industries, so that credit evaluation can be carried out efficiently; even blacklist systems can be incorporated to thoroughly regulate the behavior of people using shared products, subtly export the concept of sharing.

\subsection{Improve the credit information system and enhance personal credit}

Enterprises can incorporate cycling records into their personal credit system, establish a blacklist system, use technology to monitor the use of cyclists in real time, conduct regular quality promotion and legal publicity and strengthen the binding behavior of users. The government can jointly develop a user credit system, such as drawing on Airbnb's ID card certification, planning parking places, etc. Even the government can discuss with the enterprise to improve the domestic bicycle traffic regulations. For example, Shanghai, China, requires that the shared bicycle be under 12 years old.

\section{Conclusion}

Under the new normal, China faces economic problems such as low-end overcapacity, insufficient high-end production capacity and mismatch between supply and demand. The sharing economy effectively revitalizes idle economic factors and improves social resource allocation through advanced technologies such as mobile Internet, big data and cloud computing. And the use of efficiency, so sharing the economy is an inevitable choice for China's economic development. Sharing bicycles as an important representative of the sharing economy has developed rapidly in a short period of time, demonstrating its huge market potential. While sharing bicycles to solve the "last mile" travel problem, it also responded to the government and people's call for "green travel." Therefore, the maintenance of shared bicycles is a must-have and requires strategizing. Both the country and the enterprise should take care of the development of shared bicycles and transfer the sharing concept to the people, so that more people can benefit from the shared economy.

\section{References}

[1] Yang Lu,Savvas Papagiannidis,Eleftherios Alamanos. Exploring the emotional antecedents and outcomes of technology acceptance[J]. Computers in Human Behavior,2019,90.

[2] Jussi Nikkinen,Timo Rothovius. The EIA WPSR release, OVX and crude oil internet interest[J]. Energy,2019,166.

[3] Baranes,Savage. Access prices, unbundling and product variety in European Internet markets[J]. Applied Economics,2018,50(60).

[4] Internet Directory for the Earth Sciences[J]. Rocks \&amp; Minerals,2019,94(1).

[5] Li Cai,Nina Dai,Zefu Tan. Research on mathematical model and calculation simulation of wireless sensor solar cells in Internet of Things[J]. EURASIP Journal on Wireless Communications and Networking,2018,2018(1). 